ARTICLE

https://doi.org/10.1057/s41599-019-0217-x

\title{
Framing effects on public support for carbon capture and storage
}

\author{
Lorraine Whitmarsh ${ }^{1}$, Dimitrios Xenias ${ }^{1} \&$ Christopher R. Jones ${ }^{2}$
}

\begin{abstract}
Carbon Capture and Storage (CCS) involves trapping carbon dioxide $\left(\mathrm{CO}_{2}\right)$ from power generation and heavy industrial processes and directing it into long-term geological storage (e.g., in depleted oil fields or saline aquifers). In doing so, CCS could facilitate global carbon abatement efforts. Yet, it remains controversial with high-profile public opposition to particular CCS developments. For instrumental, normative and substantive reasons, it is increasingly recognised that public acceptance of CCS as a vital precondition for its commercial-scale rollout. While much is known about factors influencing public support for CCS, relatively few cross-national studies have so far been undertaken. Here, we present findings from a large-scale international experimental study of public perceptions of CCS, to examine how individual, geographical and informational factors influence support for CCS. In particular, we compare the lens through which CCS is seen - as a 'techno-fix' climate change solution, as reusing a waste product (through Carbon Dioxide Utilisation [CDU]), or as part of a systemic approach to climate change mitigation. Pairing CCS with CDU led to higher support for CCS, although information frames interacted with national and individual-level factors. Depending on which CCS lens is chosen, different groups will be more or less likely to support CCS implementation. As with other issues, targeting CCS information to audience values is likely to be more effective than untargeted communication. Our findings also show mentioning (modest) costs of deploying CCS can lead to lower support. Discussing CCS costs should be done in the context of costs of broader energy system transformation and of not mitigating climate change so that the public can deliberate over the relative risks and benefits of CCS and alternatives in the context of broader sustainability pathways.
\end{abstract}

\footnotetext{
${ }^{1}$ School of Psychology, Cardiff University, Cardiff, United Kingdom. ${ }^{2}$ Environmental Psychology Research Group, School of Psychology, University of Surrey, Guildford, United Kingdom. Correspondence and requests for materials should be addressed to L.W. (email: WhitmarshLE@cardiff.ac.uk)
} 


\section{Introduction}

arbon Capture and Storage (CCS) involves trapping carbon dioxide $\left(\mathrm{CO}_{2}\right)$ from power generation and heavy industrial processes and directing it into long-term geological storage (e.g., in depleted oil fields or saline aquifers). In doing so, CCS is seen as essential for facilitating global carbon abatement efforts (IPCC, 2014; IEA, 2013). Along with energy efficiency and certain other mitigation options, it is argued to be a cost-effective measure for reducing $\mathrm{CO}_{2}$ emissions that cause climate change (Praetorius and Schumacher, 2009). While CCS may offer environmental and economic benefits (van Egmond and Hekkert, 2012), it remains controversial with high-profile public opposition to particular CCS developments. It is increasingly recognised that public acceptance of CCS as a vital precondition for its commercial-scale rollout (RCUK, 2010; Wennersten et al., 2015).

Public engagement with CCS is important for a range of reasons. From one point of view, it may serve to mitigate public opposition to developments-for example, those seen in Barendrecht in the Netherlands (Bellona, 2010). However, there are also reasons of democratic governance and decision quality that argue in favour of public views being considered in CCS decisionmaking. Fiorino (1990) distinguished three main rationales for public engagement: normative, substantive, and instrumental. That is, public engagement should involve those individuals who have a stake in the decision (e.g., communities affected by siting decisions; voters in the case of public funded projects); it can improve the quality of decision-making by drawing on diverse knowledge and values; or it may be used with a specific goal to raise public awareness, increase risk or product acceptance, or foster trust in experts, developers or government (Whitmarsh et al., 2009). A first step for engaging the public is to understand their perceptions. Here, we present findings from an international study of public perceptions of CCS, to examine how individual, geographical and informational factors influence support for CCS.

\section{Public perceptions of CCS}

Research on public perceptions of CCS highlights low public awareness of CCS across countries (Demski et al., 2013; Ashworth et al., 2015; Chen et al., 2015), and various misperceptions (De Best-Waldhober et al., 2011; Poumadère et al., 2011). Views expressed are often ambivalent: concerns include the long-term viability of CCS, its safety, association with coal mining, and financial cost; while people are positive about the potential of CCS to reduce carbon emissions thereby helping combat climate change (Demski et al., 2013; Poumadère et al., 2011). Support for CCS is often contingent on CCS being not only safe but also just one part of a wider strategy for achieving cuts in $\mathrm{CO}_{2}$ emissions. However, there is much heterogeneity in CCS perceptions, with a range of factors influencing support. The key factors involved in community support for CCS include the characteristics of the project; the engagement process; risk perceptions; the actions of the stakeholders; the characteristics of the community, and the socio-political context (Poumadère et al., 2011).

The majority of studies investigating perceptions of CCS have been conducted within individual countries; there have been notably fewer cross-cultural studies of CCS perceptions (and even fewer covering more than one continent), making direct comparisons across studies difficult From the cross-cultural studies that have been conducted in Europe, it seems that awareness is particularly high in the Netherlands (potentially due to the high profile nature of the Barendrecht case; Bellona, 2010), whereas elsewhere awareness is lower, with Europeans typically holding fairly mixed and ambivalent views towards CCS (Upham and
Roberts, 2011; Eurobarometer, 2011; Reiner et al., 2011). There are, however, notable differences between continents (L'Orange Seigo et al., 2014; Ashworth et al., 2013). For example, Canadians seem to be more accepting than Swiss publics, perhaps due to their different experience of (and dependence on) fossil fuel industries (L'Orange Seigo et al., 2014). Even within individual countries, research points to regional variations in perceptions, with one German study finding those living closer to actual or proposed sites less supportive of CCS (Braun, 2017).

Extending beyond simple geographical considerations, characteristics of the proposed scheme (e.g., feedstock, aspect of the capture or storage process being considered) have been found to interact with public opinion. One experimental Swiss study found local opposition to pipelines and storage, but this opposition disappeared when $\mathrm{CO}_{2}$ from a biogas-fired plant was used for the injection (Wallquist et al., 2012). Similarly, a survey of residents in Germany, Netherlands, UK, Poland and Spain found local opposition to storage, but a more complex, quadratic relationship between local CCS project support and proximity to capture sites, with the most positive respondents those living closest (Eurobarometer, 2011). It is thus important to consider geographical and scheme-specific factors, as well as psychological factors, in understanding public support for CCS (Poumadère et al., 2011).

\section{Framing effects and CDU}

In addition, the way in which CCS information is presented or 'framed' and audience characteristics (e.g., knowledge, values) also influence public views on the technology (van Knippenberg and Daamen, 1996; Brunsting et al., 2013; Broecks et al., 2016). Consequently, providing information about CCS does not always allay fears or change attitudes (Upham and Roberts, 2011; Brunsting et al., 2013; Wallquist et al., 2011; Braun et al., 2018). Consistent with the pervasive confirmation bias in information processing, whereby initial beliefs or feelings filter whether or how further information is perceived (De Bruin and Wong-Parodi, 2014), information may also exacerbate or confirm concerns or, conversely, reinforce positive attitudes. For example, Dutch and Scottish participants in one study became more negative after reading information about CCS, whereas Canadian and Australian participants became more positive (Ashworth et al., 2013). The notion of 'framing' spans several social science disciplines and theories. Framing emphasises certain elements of a message and uses certain language or imagery to create particular associations or meanings; as such, framing provides interpretive shortcuts' to reduce complexity of information processing for audiences (Nisbet, 2009; Chong and Druckman, 2007). Critically, and consistent with persuasion theories (Petty and Cacioppo, 1986), framing is most effective when it resonates with an audience's prior understanding and values (Whitmarsh and Corner, 2017); for example, emphasising social or economic development benefits of environmental protection works better to persuade climate change sceptics to act pro-environmentally than focussing on climate change risks (Bain et al., 2012).

Consistent with this, framing CCS as dealing with 'waste' seems to be more persuasive in encouraging support than framing it in terms of climate or economic benefits (Jones et al., 2017a). The current study develops this finding to provide, for the first time, insights into representative public perceptions of carbon dioxide utilisation (CDU)-a technical process of recycling $\mathrm{CO}_{2}$ to make new products (e.g., cement and plastics)-on support for the technology (Jones et al., 2017b). We explore the dynamic between CCS as a sufficient climate change mitigation strategy vs. the additional need for behaviour change, and the possible added value of CDU. Small-scale, deliberative research conducted in the 


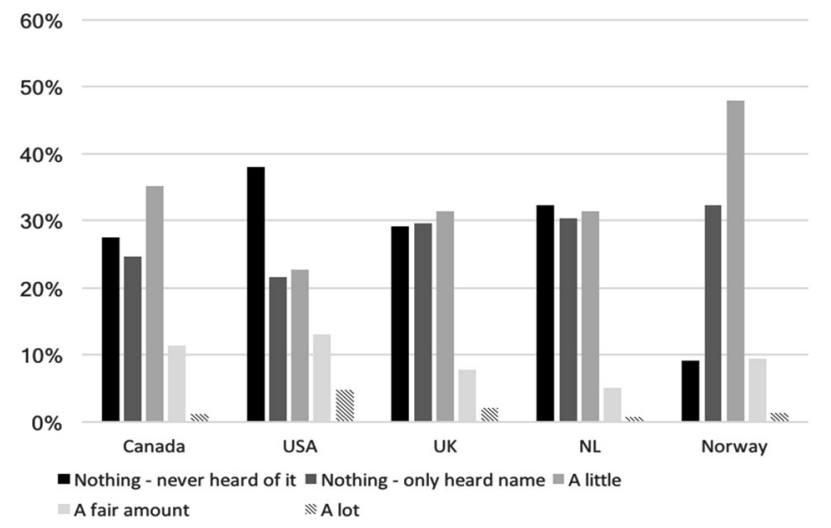

Fig. 1 Public awareness of CCS, by country. Note to Fig. 1. Difference between countries in public awareness of CCS is significant: $\chi^{2}(16, N=$ $5406)=398.60, p<.001)$

UK and Germany suggests individuals express cautious support for CDU as a way of generating economic and possibly environmental benefits; while concerns include practical and technical issues, as well as more fundamental, moral worries that CDU (like CCS; Demski et al., 2013) represents a techno-fix solution or 'delaying tactic' that might prevent the required societal change to tackle climate change (Jones et al., 2017a, b). These moral concerns are particularly evident amongst those with strong environmental values. Other work suggests 'avoiding waste' can be a powerful frame for persuading publics about environmental issues, even reducing climate change scepticism (Whitmarsh and Corner, 2017). Consistent with previous empirical and theoretical literatures (Corner et al., 2012; Chong and Druckman, 2007), we predicted that information framing would interact with individual characteristics, such as values and lifestyle. Specifically, we expected that those high in environmental values would express lower support for CCS and CDU, unless framed as part of a larger societal shift to address climate change. Conversely, we expected, consistent with the literature on identity threat and motivated reasoning (Corner et al., 2012), that those with more energyintensive lifestyles (e.g., high income) would prefer CCS when framed as sufficient for mitigating climate change, meaning lifestyle change is not required.

\section{Methods}

To provide a detailed cross-national examination of public attitudes to CCS, that includes geographical, social, psychological and informational (frames, scheme characteristics) factors, we surveyed 5406 members of the public in the UK, US, Canada, Norway and the Netherlands. These countries were selected because they reflect different stages of CCS development (including offshore and onshore storage), which were expected to influence perceptions (L'Orange Seigo et al., 2014). Due to findings of proximity effects noted above (Braun, 2017; Wallquist et al., 2012), we sampled those living close to actual or proposed CCS sites, as well as a representative national sample, in each country.

Measures and materials. Most measures used were taken or adapted from previous research (Whitmarsh et al., 2015). Items included questions of support for energy sources, attitudes to CCS, CCS risk and benefit perceptions, and a range of psychological constructs (e.g., place attachment, technophilia, environmental identity, environmental values) and demographic measures. The main measures used are described here:
CCS awareness: 'How much would you say you know about 'carbon capture and sequestration' also known as 'carbon capture and storage' (or 'CCS')?' with five response options from 'Nothing-never heard of it' to 'A lot' (see Fig. 1).

Attitudes to CCS: 'Carbon capture and sequestration (or carbon capture and storage-CCS) is the process of capturing carbon dioxide $\left(\mathrm{CO}_{2}\right)$-which contributes to climate change-from large installations such as fossil fuel power plants and heavy industries, and storing it safely underground. To what extent do you agree or disagree with these statements about Carbon Capture and Sequestration/ Storage (CCS)?' with statements as shown in Fig. 3 (items three to nine) and a seven-point response scale from Strongly disagree -3 ' to 'Strongly agree +3 ' and an 'I don't know' option (removed for analysis).

CCS risks versus benefits: 'From what you know or have heard about CCS in this country, on balance, which of these statements most closely reflects your own opinion?' with a five-point response scale: 'The benefits of CCS far outweigh the risks' (2); 'The benefits of CCS slightly outweigh the risks' (1), 'The benefits and risks of CCS are about the same' (0), 'The risks of CCS slightly outweigh the benefits' $(-1)$, and 'The risks of CCS far outweigh the benefits' $(-2)$. 'None of these' and 'don't know' were excluded from analysis. 'Total agreement' in the figure combines $+1,+2$, (and +3$)$; 'Total disagreement' combines $-1,-2$, (and -3 ).

CCS support: 'Should CCS be implemented in [name of country]? With a five-point response scale from 'Yes, definitely +2 ' to 'Definitely not -2 ' and 'I don't know' (removed for analysis)

Support for energy sources and climate change mitigation options: "How supportive or unsupportive are you of the following ways of generating power or reducing carbon emissions?' on a seven-point response scale from 'Very supportive +3 ' to 'Very unsupportive -3 '. A further response option, 'Not aware of this option', was removed for analysis. (For CCS, for example, this amounted to $35.5 \%$ of the sample). Support for CCS with cost information: 'Implementing CCS

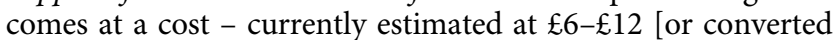
to local currencies] on the average household electricity bill per year. But if we do not implement CCS in this country now, energy bills could rise even more in the future (because more $\mathrm{CO}_{2}$ mitigation measures would be necessary). How willing would you be to accept immediate implementation of CCS if this increase in bills was avoided?' with a five-point response scale: 'Completely willing +4 ' to 'Not at all willing 0 '. This was rescaled -2 to +2 in order to compare with the CCS support question (Fig. 5).

Environmental values: a short form of the New Environmental Paradigm (NEP) scale was used comprising six statements: 'Humans have the right to modify the natural environment to suit their needs', 'Humans are seriously abusing the environment', 'Plants and animals have as much right as humans to exist', 'The balance of nature is strong enough to cope with the impacts of modern industrial nations', 'Humans were meant to rule over the rest of nature' and 'The balance of nature is very delicate and easily upset' on a five-point agreement scale from -2 (strongly disagree) to +2 (strongly agree); $(\alpha(6)=.76)$.

Place attachment: four items were used: 'I feel like I belong to the community where I live', 'I am very attached to the natural environment in my area', 'If I need advice about something I could go to someone in my neighbourhood' and 'Given the opportunity, I would like to move out of this neighbourhood' (reverse scored), on a five-point agreement scale from -2 (strongly disagree) to +2 (strongly agree); $(\alpha(4)=.62)$.

Climate change scepticism: assessed with six items: 'Claims that human activities are changing the climate are exaggerated', 
Table 1 Demographic details of sample (\% in each country)

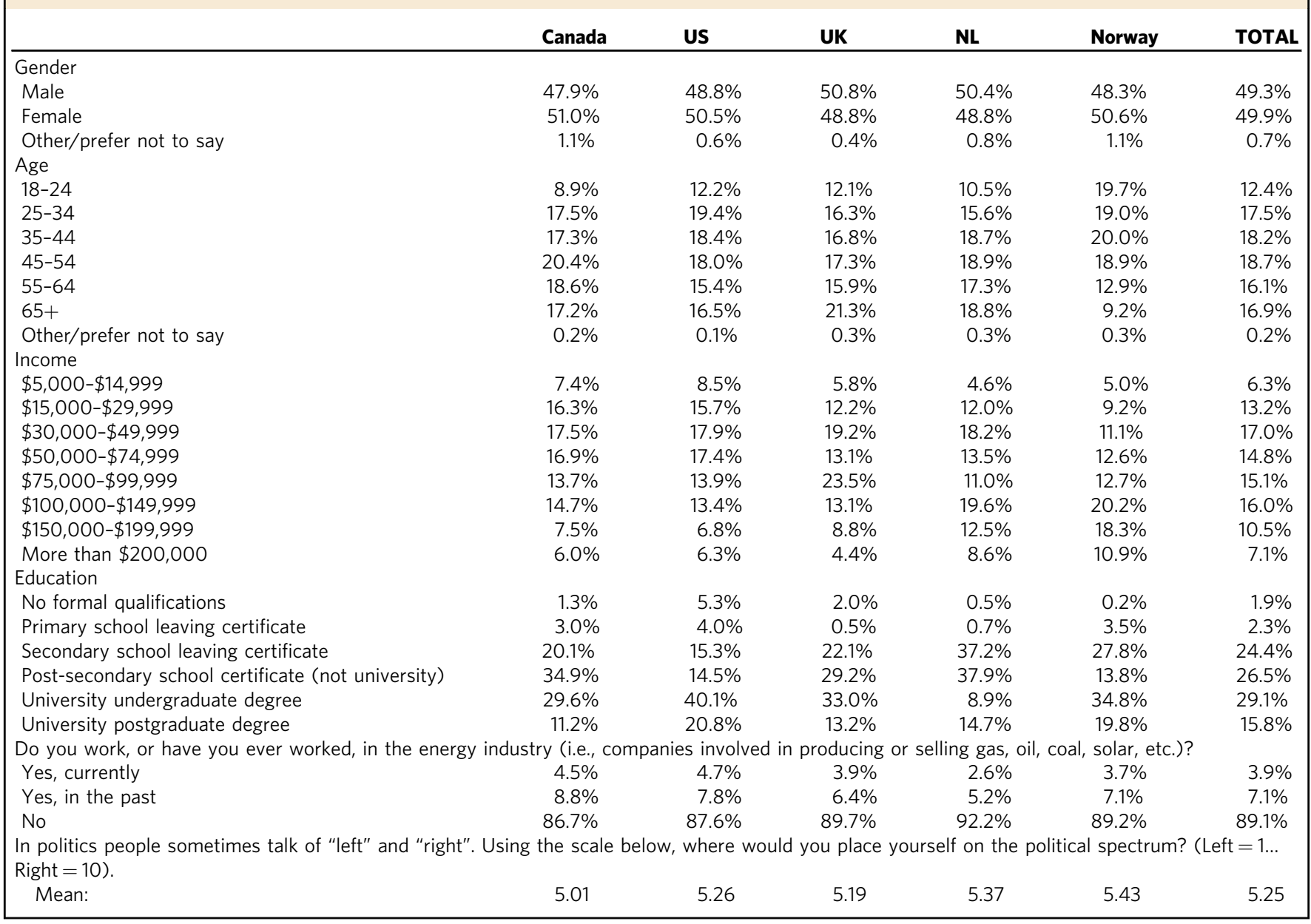

'Climate change is just a natural fluctuation in Earth's temperatures', 'There is too much conflicting evidence about climate change to know whether it is actually happening', 'It is too early to say whether climate change is really a problem', 'Too much fuss is made about climate change' and 'I am convinced that climate change is really happening' (reverse scored $) ;(\alpha(6)=.91)$.

Environmental identity: assessed with two items: 'I think of myself as someone who is concerned about the environment' and 'Being environmentally-friendly is an important part of who I am' on a five-point agreement scale from -2 (strongly disagree) to +2 (strongly agree); $(\alpha(2)=.84)$

Technophilia: assessed with a ten-item scale: 'Technology is my friend', 'I enjoy learning new computer programs / apps and hearing about new technologies', 'People expect me to know about technology and I don't want to let them down', 'If I am given an assignment that requires that I learn to use a new programme or how to use a machine, I usually succeed', 'I relate well to technology and machines', 'I am comfortable learning new technology', 'I know how to deal with technological malfunctions or problems', 'Solving a technological problem seems like a fun challenge', 'I find most technology easy to learn', and 'I feel as up-to-date on technology as my peers' on a five-point agreement scale from -2 (strongly disagree) to +2 (strongly agree); $(\alpha(10)=.94)$. Demographics: gender, age, income, education, political ideology, and experience working in the energy industry were elicited in each country (see Table 1) as these have been shown to be relevant for CCS support (Poumadère et al., 2011).

Experimental materials were developed in consultation with CCS experts and the literature. Following a description of CCS, three different experimental texts were presented according to condition:

CCS description (all conditions): Carbon capture and storage (CCS) is the process of capturing carbon dioxide $\left(\mathrm{CO}_{2}\right)$ from large installations such as fossil fuel power plants and heavy industries. Such installations emit $\mathrm{CO}_{2}$ as a wasteful by-product of power generation and manufacturing (e.g., steel, cement). Captured $\mathrm{CO}_{2}$ is then transported and stored safely so that it does not escape into the atmosphere, where it contributes to climate change. The $\mathrm{CO}_{2}$ may be stored underground as a gas, or chemically changed from a gas to a solid. Global carbon emissions amount to over 9 billion tonnes per year. Of this, over 33 million tonnes per year is currently captured by CCS.

CCS_BAU condition: CCS prevents the release of large quantities of $\mathrm{CO}_{2}$ into the atmosphere. This allows us to reduce the amount of atmospheric $\mathrm{CO}_{2}$ without having to change our way of life. For example, we will not have to fly less or use less energy at home!

$C C S+C D U$ condition: CCS prevents the release of large quantities of $\mathrm{CO}_{2}$ into the atmosphere. This allows us to reduce the amount of atmospheric $\mathrm{CO}_{2}$ without having to change our way of life. For example, we will not have to fly less or use less energy at home! CCS also allows the captured $\mathrm{CO}_{2}$ to be re-used 
Table 2 CCS project details in sampled countries (adapted from Global CCS Institute, 2018)

\begin{tabular}{|c|c|c|c|}
\hline Country & CCS project and location & Storage location & Project status and capture capacity ${ }^{\star}$ \\
\hline UK & Peterhead project, Scotland & Offshore & Scheme cancelled 2015 pre-operations, 1 Mpta \\
\hline Norway & Sleipner project, Stavanger & Offshore & Launched 1996, 1 Mtpa \\
\hline Netherlands & ROAD project, Rotterdam city & Offshore & Launched 2015 (demonstration), 1.1 Mtpa \\
\hline US & Petra Nova project, Texas & Onshore & Launched 2017, 1.4 Mtpa \\
\hline Canada & Quest project, Alberta & Onshore & Launched 2015, 1 Mtpa \\
\hline
\end{tabular}

\begin{tabular}{|c|c|c|}
\hline Country (total $N$ ) & $\begin{array}{l}\text { National } \\
\text { sample }\end{array}$ & CCS site and local sample \\
\hline UK $(N=1148)$ & $N=1053$ & $\begin{array}{l}\text { Peterhead project: } \\
\text { Peterhead (NE Scotland })+50 \mathrm{~km} \\
\text { zone }(N=95)\end{array}$ \\
\hline US $(N=1112)$ & $N=1007$ & $\begin{array}{l}\text { Petra Nova project } \\
\text { Rosenberg (Houston, Texas })+ \\
30 \mathrm{~km} \text { zone }(N=105)\end{array}$ \\
\hline Canada $(N=1110)$ & $N=1010$ & $\begin{array}{l}\text { Quest project } \\
\text { Fort Saskatchewan, (Edmonton, } \\
\text { Alberta })+20 \mathrm{~km} \text { zone }(N=100)\end{array}$ \\
\hline Norway $(N=927)$ & $N=850$ & $\begin{array}{l}\text { Sleipner project } \\
\text { Stavanger region }(N=77)\end{array}$ \\
\hline $\begin{array}{l}\text { Netherlands } \\
(N=1109)\end{array}$ & $N=1009$ & $\begin{array}{l}\text { ROAD project } \\
\text { Rotterdam city }(N=100)\end{array}$ \\
\hline
\end{tabular}

to make useful carbon-based products. These include medicines, plastics, building materials (e.g., cement) and many other things. Re-using $\mathrm{CO}_{2}$ in this way helps reduce the waste our society produces.

$C C S+L C$ condition: CCS prevents the release of large quantities of $\mathrm{CO}_{2}$ into the atmosphere. This will add to other, necessary changes to our society and lifestyle-for example, flying less or using less energy at home. Together, these actions will help slow down climate change.

Participants. Participants (total $N=5406$ ) were recruited via Qualtrics, an online participant panel provider, between July and October 2017. Participants were rewarded for their participation (with, e.g., shopping vouchers).

Our survey was conducted in the UK, US, Canada, Norway and the Netherlands, thus extending the geographic reach of previous research (mostly single country or within Europe) and allowing for cross-cultural comparison. These countries were selected because (a) they reflect different stages of CCS development (including offshore and onshore storage), which were expected to influence perceptions (L'Orange Seigo et al., 2014); and (b) because they had sufficient national and local sample representation in online participant panels (recruited via Qualtrics). Within Europe, countries with CCS activities (and associated public debate) include the Netherlands, Germany, France, Spain, Norway and Poland. A combination of how established CCS was in each country, the extent and nature of public debate about CCS, sample availability, and survey costs eventually narrowed our European selection to the UK, Norway and the Netherlands (see Table 2). Given that there is evidence of existing differences in CCS perceptions across continents (L'Orange Seigo et al., 2014; Ashworth et al., 2013), we also wanted to compare our European sub-sample with respondents from a different continent. North America (specifically Canada and the US) was selected given the extent of existing CCS activity there (see Table 2). Selecting Canada and the US for inclusion in the study also enabled a comparison of CCS perceptions within a set of five Western democracies and provided best balance of cultural comparability and diversity for the available study resources.

Two samples in each country (UK, US, Canada, Norway, the Netherlands)-a national sample and a local sample-were recruited as shown in Table 3. The national sample was demographically representative (according to latest census data) of each of the five countries in terms of gender and age. The local samples were identified as living close to a current or proposed CCS site (including processing, pipeline and storage locations). Proximity to the CCS site had to be balanced with inhabited and sufficiently populous areas, in order to ensure sufficient samples were recruited (with the aim of achieving $N=100$ for each site), so there is some variation in the radius around each site.

Design and procedure. All participants gave informed consent, completed screening questions (to ensure regional and demographic quotas were met) and were then presented with questions about energy/mitigation options, CCS attitudes, and risk/benefit perceptions. They were then randomised to one of three information conditions:

- CCS without lifestyle change (CCS_BAU) $(N=1424)$

- CCS with CDU (CCS + CDU) $(N=1397)$

- CCS with lifestyle change (CCS + LC) $(N=1384)$

After reading the information, participants completed manipulation checks (to assess whether they had properly read the information provided; see Table 4), and then completed dependent and independent variables, before being debriefed.

\section{Results}

Individual and national differences in CCS support. Findings showed that, consistent with previous research (Demski et al., 2013), public awareness of CCS is low (Fig. 1), although there are cross-national differences in awareness, with the Norway sample showing the highest levels and the US sample the lowest. Despite more awareness in Norway, the greatest support for CCS is evident in the UK (Fig. 2). Lowest support is found in the Netherlands. Local samples (i.e., close to current or potential CCS sites) are more supportive of CCS being implemented than national samples, particularly in the UK. Analysis of variance (ANOVA) to examine the effects of nation and locality on CCS support (preinformation) indicates both main effects and interaction effects (shown in Fig. 1). All countries significantly differ from one another, except the UK and Norway, at $p<.01 ; F(4,3665)=19.06$, $\left.p<.001 ; \eta^{2}=.02\right)$. Local samples are significantly more supportive of CCS being implemented than are national samples; $F$ $\left.(1,3665)=28.85, p<.001 ; \eta^{2}=.008\right)$.

Attitudes to CCS are ambivalent though moderately positive (Fig. 3). More of the public agree that CCS should be implemented in their country than disagree. Most express concern about leaks from CCS and that it will encourage 


\section{Table 4 Results of manipulation checks for each condition}

\begin{tabular}{|c|c|c|c|}
\hline & CCS_BAU & CCS + CDU & CCS + LC \\
\hline CCS allows us to reduce the amount of atmospheric $\mathrm{CO}_{2}$ without having to change our way of life. & $75.5 \%$ & & \\
\hline CCS allows the captured carbon dioxide $\left(\mathrm{CO}_{2}\right)$ to be re-used to make useful carbon-based products. & $11.8 \%$ & $83.1 \%$ & $18.2 \%$ \\
\hline CCS is an essential part of cement manufacturing. & $0.9 \%$ & $3.9 \%$ & $0.7 \%$ \\
\hline CCS contributes to the sustainability of marine environments & & $6.0 \%$ & \\
\hline CCS converts carbon dioxide $\left(\mathrm{CO}_{2}\right)$ to a liquid which is used in steel manufacturing & & $5.4 \%$ & $3.6 \%$ \\
\hline
\end{tabular}

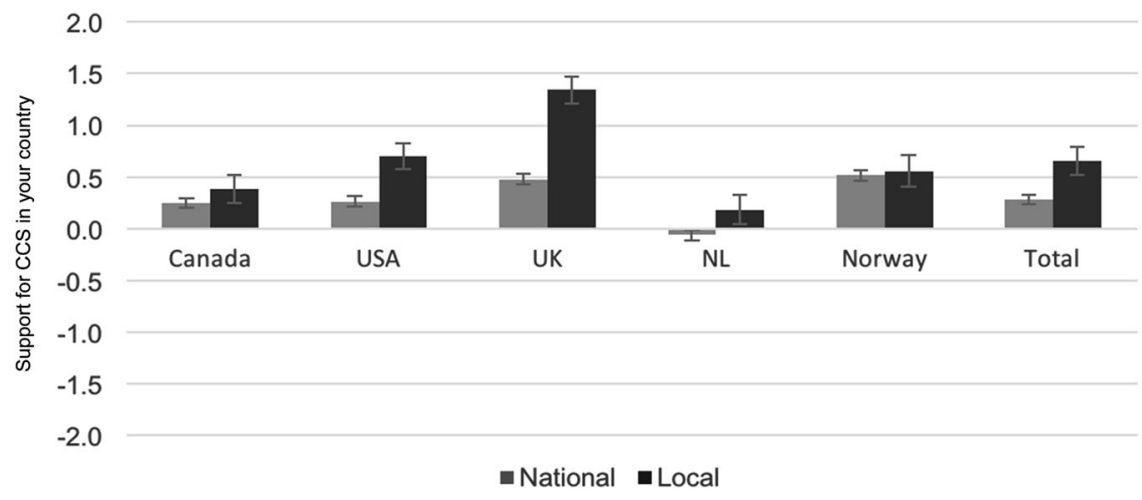

Fig. 2 National and regional differences in support for CCS implementation (error bars: +/- SE)

dependence on fossil fuels, while most also believe CCS could help mitigate climate change and help the economy. Comparison of responses to the post-information CCS support question $(\mathrm{M}=0.45 ; \mathrm{SD}=1.26)$ and the cost-framed support question $(\mathrm{M}=0.39 ; \mathrm{SD}=1.30)$, asked immediately afterwards, show these differ significantly: $\mathrm{t}(4209)=4.13, p<.001)$; see Fig. 3 .

Comparing predictors of CCS support, we find nationality to be the strongest predictor; other predictors include proximity, place attachment, being younger, being male, right-wing political ideology, climate change belief, technophilia, stronger environmental identity but lower environmental values, as well as working in the energy industry (Table 5).

Framing effects on CCS support. While CCS attitudes are moderately positive, renewables and energy demand reduction see higher levels of support (Fig. 4). However, when CCS is paired with different energy sources or processes, support for it differs compared to CCS in general: bioenergy with CCS is more supported; while shale gas, underground coal gasification and heavy industry with CCS are less supported.

Information provision also influences CCS attitudes. Compared to support for CCS implementation before costs are mentioned, support is lower when CCS costs per household is mentioned (Fig. 5). Similarly, when participants are exposed to the experimental component of the survey (information about CCS framed as either (a) business as usual [BAU], (b) with carbon dioxide utilisation [CDU], or (c) with lifestyle change), we find the CDU-framed information leads to greater support for CCS implementation than either of the other two information frames (Fig. 6). ANOVA to examine information frame effects on CCS support shows the CDU condition elicits significantly higher support $(\mathrm{M}=.530, \mathrm{SD}=1.25)$ than the BAU $(\mathrm{M}=.383$, $\mathrm{SD}=1.28)$ or $\mathrm{CCS}+$ frame $(\mathrm{M}=.439, \mathrm{SD}=1.26)$, as shown in Fig. $\left.4 ; F(2,4209)=4.92, p=.007 ; \eta^{2}=.002\right)$. Post-hoc Bonferroni analysis indicates the differences between CDU frame and BAU frame are significant $(p=.006)$; but differences between other frames are not.

Analysis of change in CCS support (post-information minus pre-information support) in each condition (Table 6) shows the different messages affect different types of people. Norwegians express significantly higher support for CCS in a BAU scenario; while those with strong environmental values express significantly lower support. Climate sceptics and those with no/few children expressed more support for CCS when CDU-framed. Men, older people, and those with high incomes showed lower support for CCS after reading the CCS + lifestyle change message.

\section{Discussion}

CCS is argued to be a key element of efforts to tackle climate change, but it remains a controversial technology amongst the general public in many countries. Our results provide important and novel insights into public attitudes to CCS, highlighting the importance of geographical, psychological and informational factors in shaping support for CCS implementation. First, our findings expose strong cross-national differences in awareness and support for CCS, with Norway most aware and the UK most positive. Previous European cross-national research (conducted in 2011) found highest levels of awareness in the Netherlands, but did not include Norway in their sample (Eurobarometer, 2011; Reiner et al., 2011). Also, the six year time gap between the two studies and different sampling methodologies (random probability sampling in Eurobarometer vs. our use of online panels) could explain the somewhat lower levels of awareness in the Netherlands we observed. We found lowest support for CCS in the Netherlands, likely at least in part due to its history of opposition to proposed CCS development (i.e., Barendrecht; De Best-Waldhober et al., 2011). Indeed, country of residence is the strongest predictor of CCS support, highlighting the importance of cross-cultural research in this area. Proximity to proposed or current CCS facilities was also important, with proximal samples 


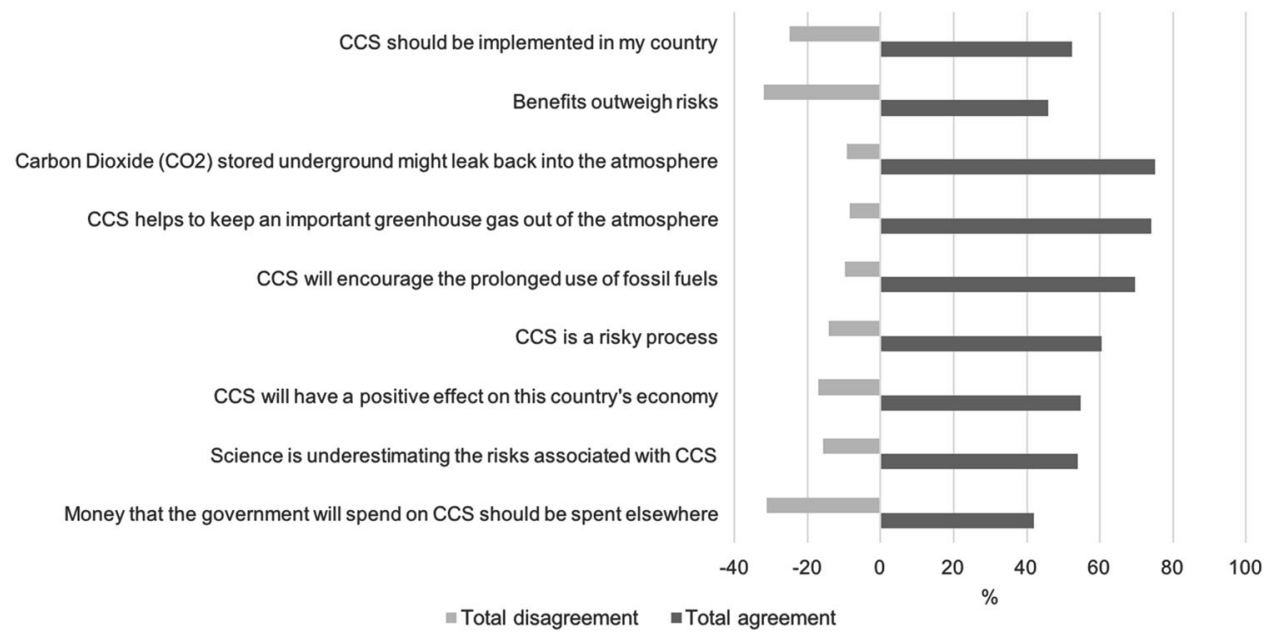

Fig. 3 Public attitudes to CCS

\begin{tabular}{|c|c|c|c|}
\hline \multicolumn{4}{|l|}{ CCS support (Pre-info) } \\
\hline & Beta & $t$ & Sig. \\
\hline (Constant) & & 4.68 & 0.00 \\
\hline USA & 0.02 & 0.86 & 0.39 \\
\hline UK & 0.10 & 5.11 & 0.00 \\
\hline NL & -0.09 & -4.55 & 0.00 \\
\hline Norway & 0.09 & 4.26 & 0.00 \\
\hline Local & 0.09 & 5.71 & 0.00 \\
\hline (Constant) & & 0.28 & 0.78 \\
\hline USA & 0.00 & 0.00 & 1.00 \\
\hline UK & 0.11 & 5.48 & 0.00 \\
\hline NL & -0.08 & -3.83 & 0.00 \\
\hline Norway & 0.10 & 4.80 & 0.00 \\
\hline Local & 0.08 & 5.10 & 0.00 \\
\hline Climate scepticism & -0.08 & -3.94 & 0.00 \\
\hline Technophilia & 0.13 & 8.11 & 0.00 \\
\hline Environmental Identity & 0.12 & 6.44 & 0.00 \\
\hline NEP (Env. values) & -0.12 & -5.84 & 0.00 \\
\hline (Constant) & & -1.66 & 0.10 \\
\hline USA & 0.00 & 0.09 & 0.93 \\
\hline UK & 0.11 & 5.56 & 0.00 \\
\hline $\mathrm{NL}$ & -0.09 & -4.36 & 0.00 \\
\hline Norway & 0.08 & 3.77 & 0.00 \\
\hline Local & 0.06 & 3.82 & 0.00 \\
\hline Climate scepticism & -0.10 & -4.87 & 0.00 \\
\hline Technophilia & 0.10 & 5.71 & 0.00 \\
\hline Environmental Identity & 0.11 & 5.48 & 0.00 \\
\hline NEP (Env. values) & -0.10 & -4.50 & 0.00 \\
\hline Age & -0.06 & -3.40 & 0.00 \\
\hline Gender (male) & 0.06 & 3.44 & 0.00 \\
\hline Household income & 0.03 & 1.46 & 0.14 \\
\hline Education & -0.01 & -0.63 & 0.53 \\
\hline Political ideology & 0.06 & 3.42 & 0.00 \\
\hline Work(ed) in energy industry & 0.09 & 5.12 & 0.00 \\
\hline Place attachment & 0.05 & 2.74 & 0.01 \\
\hline
\end{tabular}

Note: Significant predictors are shown in bold

Model $1 R^{2}=.040^{*}$; Model $2 R^{2}=.081^{\star} ;$ Model $3 R^{2}=.099^{\star}\left({ }^{\star} \Delta R^{2} p<.001\right)$

(i.e., close to current or potential CCS sites), particularly in the UK, more supportive of CCS than the general national samples perhaps because of their history and dependence on energy industry for employment and greater familiarity with the technology (L'Orange Seigo et al., 2014). This finding that proximal communities were more supportive of CCS than general public

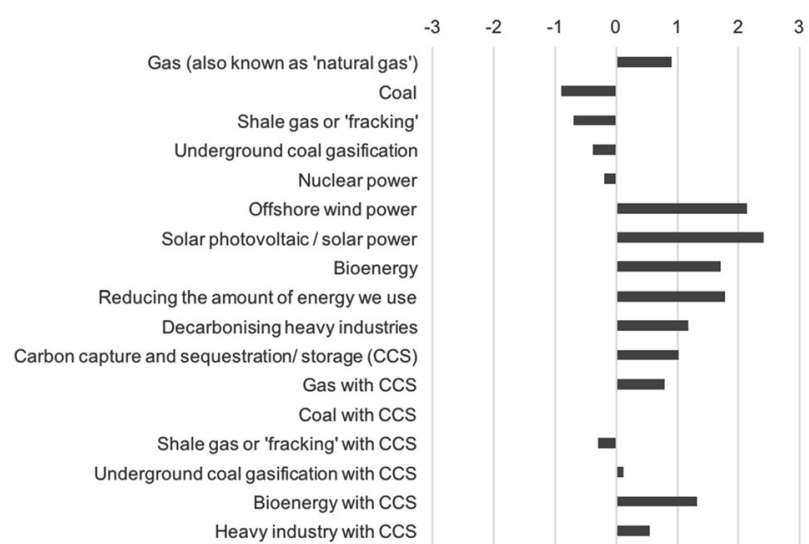

Fig. 4 Public support for energy sources and climate change mitigation options, including CCS

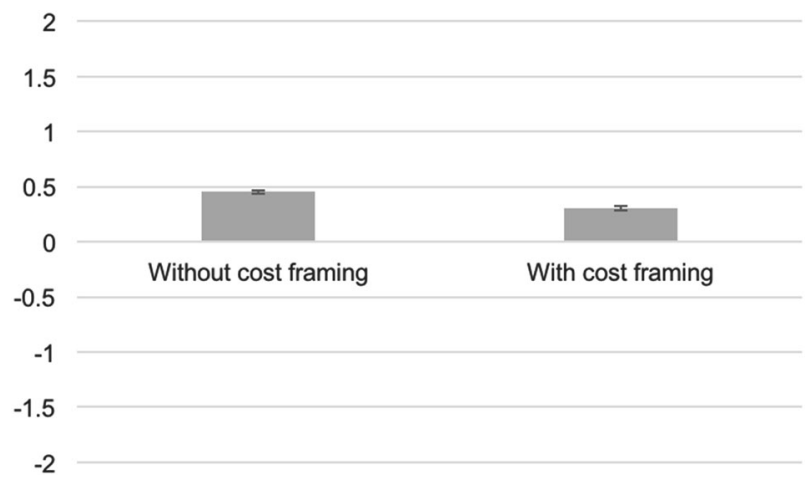

Fig. 5 Effect of cost information on CCS support (error bars: +/- SE)

samples is partly consistent with prior research in this area. Such research has observed a degree of 'YIMBYism' (Yes In My Backyard) around proposed carbon capture facilities, with local objection tending to be more likely around proposed storage sites (Braun, 2017; Eurobarometer, 2011). Within our research, our selection of 'local' samples was determined by proximity to current or proposed CCS sites, including processing, pipeline and/or storage locations. It is possible that using this definition we inadvertently sampled a greater number of people living adjacent to capture vs. storage sites. If so, this could help to account for 


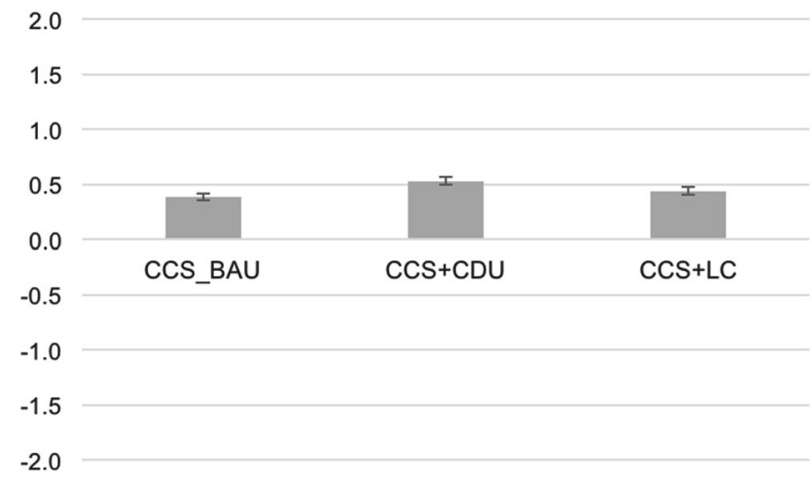

Fig. 6 Effect of different information frames on CCS support (error bars: $+/-\mathrm{SE}$ ). Note to Fig. 6. CCS-BAU was the 'business as usual' CCS frame, stating lifestyles would not need to change; $C C S+C D U$ included a description of $\mathrm{CDU}$ through which waste $\mathrm{CO}_{2}$ would be recycled to make new products; CCS + LC described CCS as part of a range of other changes, including lifestyle changes, to tackle climate change

overall positive proximity (i.e., YIMBY) effect observed in our sample. More generally, though, the research on local support and opposition to new infrastructure calls into question assumptions that local development is always opposed by those living closest to it (so-called 'NIMBYism'; Not In My Backyard); rather, opposition depends on how the particular development is conceived of in relation to residents' attachment to and understanding of (e.g., as 'industrial', 'natural') the local area (DevineWright, 2009, 2011). Where communities are supportive of a proposed development (YIMBY), this tends to be where there is identification with and/or (anticipated) reliance upon the proposed infrastructure (Warren et al., 2005; Eiser et al., 1995). Consistent with this, communities hosting CCS projects would stand to benefit economically from the jobs and revenue the industry would provide. Further, the areas in which CCS facilities are likely to be built are typically sites where there is existing (analogous) industry. Subjective familiarity with such industry could serve to reduce the perceived risks associated with new infrastructure, thus yielding a greater acceptance (or tolerance) of CCS within earmarked 'host' communities.

Second, we find framing affects CCS support in several ways. Consistent with previous work (Wallquist et al., 2012), pairing CCS with bioenergy (i.e., 'BECCS') leads to more support; while we also find fossil fuel and industry pairings see CCS less supported, suggesting BECCS is likely to be more widely accepted than most current (fossil) CCS schemes. Given the importance of BECCS to many climate change mitigation scenarios (IPCC, 2014), this is encouraging. In addition, compared to support for CCS implementation before costs are mentioned, support reduces when CCS costs per household were mentioned (despite these being very modest- $\$ \mathbb{E} 6-12$ per year-and the focus of the information being on future greater costs being avoided through CCS implementation now). This highlights a need for caution when discussing costs; if the public have no expectation that CCS will have cost implications for households, then even stressing the lower costs of CCS than alternative mitigation options may backfire and reduce support.

Similarly, when participants are exposed to the experimental component of the survey (information about CCS framed as either 'business as usual', with CDU, or with lifestyle change), we find the CDU-framed information leads to greater support for CCS implementation than either of the other two frames. Describing how $\mathrm{CO}_{2}$ might be recycled to make new products (i.e., via CDU) may help persuade publics of the benefits of CCS (Jones et al., 2017a, b). Frame preference varies as a function of national and individual factors, however. Perhaps because of their extant support for and reliance on CCS, Norwegians are significantly more likely to support CCS in a BAU scenario. Conversely, those with stronger environmental values significantly reduce support for CCS in a BAU scenario, suggesting a preference for more significant change to address climate change. Interestingly, and consistent with previous research on climate change framing (Whitmarsh and Corner, 2017), CDU information apparently increases CCS support amongst climate sceptics. This is intriguing and may suggest waste framings serve to reduce identity threat associated with climate change belief (Kahan et al., 2011); or simply that highlighting CCS' utility beyond climate mitigation raises support amongst those who do not believe in climate change. Among those who showed decreased support for CCS in the CCS with lifestyle change framing were those on high incomes, perhaps because of the implied threat to energyintensive lifestyles (which is associated with higher incomes). This is consistent with previous research on framing, motivated reasoning and identity threat, and reinforces the need to find more value-consistent messaging to communicate climate change and associated mitigation options (Bain et al., 2012; Chong and Druckman, 2007).

\section{Conclusions and implications}

Overall, our results show attitudes to CCS vary widely across countries, regions and individuals; and that different frames influence CCS support. Critically, CCS may be seen through different lenses: as a 'techno-fix' (business as usual) solution to climate change, as a means of avoiding waste and supporting a more circular economy (CDU), or as part of a systemic package of climate change mitigation options that includes lifestyle change. Depending on which of these lenses is chosen, different groups will be more or less likely to support CCS implementation in their country.

For those interested in promoting public engagement with CCS, our findings have important implications. First, it should not be assumed that those who live closest to CCS developments will necessarily oppose them; indeed, depending on their local history (e.g., relationships to and familiarity with heavy industry, place identity, etc.) and their subjective understandings of the costs, risks and benefits of the technology, they may even be more favourable. However, neither local opposition nor local support should be assumed a priori; rather a process of deliberative engagement with communities is important for exploring local perceptions, addressing concerns, managing risks and distributing benefits (Devine-Wright, 2011). As noted at the outset, amongst the rationales for public engagement, involving publics and communities in decision-making about CCS developments can improve decision quality, as well as potentially mitigating opposition (Fiorino, 1990).

Second, as noted, framing is a potentially powerful tool for shaping audience perceptions (Chong and Druckman, 2007). This is likely to be the case particularly for issues like CCS and CDU where attitudes are not yet developed (due to low awareness) or are ambivalent, and therefore more malleable in the presence of new information (Jones et al., 2017a; Whitmarsh et al., 2015). As with other issues (Petty and Cacioppo, 1986), targeting CCS information to audience values and situations is likely to be more effective than untargeted communication. Our results highlight in particular the benefits for CCS communication of affiliating the technology with CDU. This has been suggested in prior work (Jones et al., 2017a), and would appear to be particularly relevant to contexts where CCS is not outright rejected as a technology option (like in the UK). Previous research shows costs are a stumbling block to public support for CCS (Ashworth et al., 


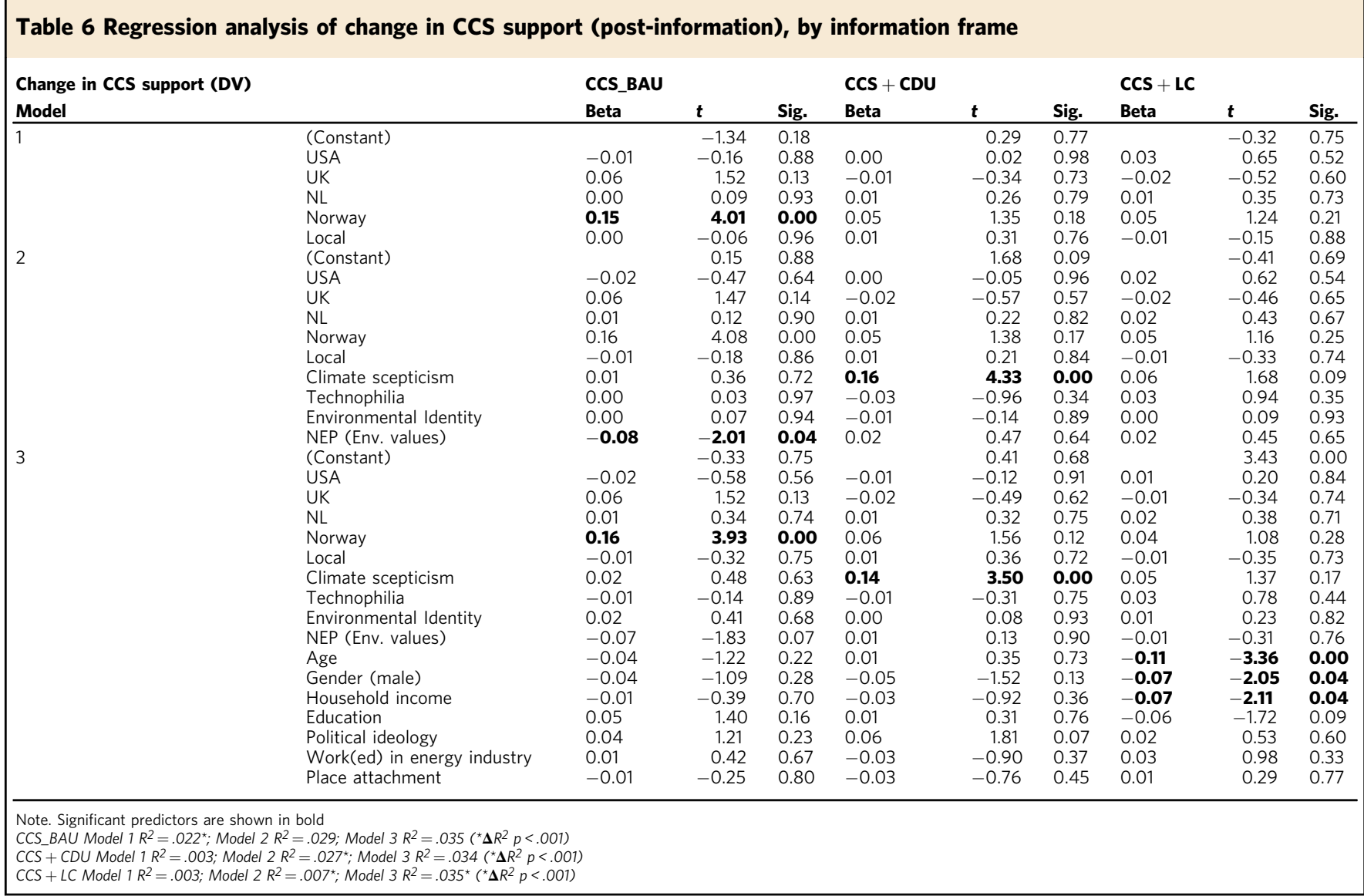

2015). Our findings demonstrate that even indicating these costs are modest can backfire and reduce support. On the basis of the current study, we feel that discussing the costs of CCS should be done in the context of the cost of broader energy system transformation (or of not mitigating climate change) so that the public can deliberate the relative risks and benefits of CCS in the context of broader sustainability pathways (Demski et al., 2015). Such public debate and deliberation is critical in light of ethical concerns about negative emissions technologies, including CCS, and their role in desirable societal futures (Lenzi et al., 2018). Our experimental texts were designed to explore responses to CCS in relation to different frames; one of the frames posed CCS as an alternative to lifestyle change when in reality both will be required in order to limit global warming to 1.5 or 2 degrees above preindustrial levels (Lenzi et al., 2018). This arguably highlights a limitation of brief framing studies or simple, top-down information-based interventions in comparison to more participatory and deliberative approaches. Using more deliberative approaches can allow for the provision of more information and nuanced debate, allowing for greater reflection on the complexities surrounding target issues (Lovan et al., 2004). That said, to the extent that people will often rely on a small amount of information when forming their opinions of technological innovation (e.g., from engaging with brief news reports), our study could be seen to reflect how people might be expected respond to news about CCS in everyday settings (Upham et al., 2015).

Finally, our research suggests the importance of greater collaboration between the CCS and CDU research communities. Notwithstanding tensions between these communities, we show there could be value in the unification of the technologies from a public perception angle. More generally, our findings speak also to the need for greater collaboration between social scientists and the engineering community around the research, development and deployment of new technologies (Jones and Jones, 2016). We show here how social scientific theories (e.g., framing) can shed light on how information about emerging technologies like CCS and CDU are conveyed to a public audience and the implications this has for public support for their deployment in a number of countries.

\section{Data availability}

The datasets analysed during the current study are not publicly available to allow for publication of findings by the authors. They are available from the corresponding author on reasonable request.

Received: 23 August 2018 Accepted: 20 December 2018 Published online: 19 February 2019

\section{References}

Ashworth P, Einsiedel E, Howell R, Brunsting S, Boughen N, Boyd A et al. (2013) Public preferences to CCS: How does it change across countries? Energy Procedia 37:7410-7418

Ashworth P, Wade S, Reiner D, Liang X (2015) Developments in public communications on CCS. Int J Greenh Gas Control 40:449-458

Bain PG, Hornsey MJ, Bongiorno R, Jeffries C (2012) Promoting proenvironmental action in climate change deniers. Nat Clim Change 2:600-603

Bellona (2010) CCS communication: lessons learnt from Barendrecht. http:// bellonaorg/news/ccs/2010-11-ccs-communication-lessons-learnt-frombarendrecht. Accessed 15 Aug 2017

Braun C (2017) Not in My Backyard: CCS sites and public perception of CCS. Risk Anal 37:2264-2275 
Braun C, Merk C, Pönitzsch G, Rehdanz K, Schmidt U (2018) Public perception of climate engineering and carbon capture and storage in Germany: survey evidence. Clim Policy 18(4):471-484

Broecks KPF, van Egmond S, van Rijnsoever FJ, Verlinde-van den Berg M, Hekkert MP (2016) Persuasiveness, importance and novelty of arguments about Carbon Capture and Storage. Environ Sci Policy 59:58-66

Brunsting S, De Best-Waldhober M, Terwel BW (2013) 'I reject your reality and substitute my own!' Why more knowledge about $\mathrm{CO}_{2}$ storage hardly improves public attitudes. Energy Procedia 37:7419-7427

Chen ZA, Li Q, Liu LC, Zhang X, Kuang L, Jia L et al. (2015) A large national survey of public perceptions of CCS technology in China. Appl Energy 158:366-377

Chong D, Druckman JN (2007) Framing theory. Annu Rev Political Sci 10 (1):103-126

Corner A, Whitmarsh L, Xenias D (2012) Uncertainty, scepticism and attitudes towards climate change: biased assimilation and attitude polarization. Clim Change 114:463-478

De Best-Waldhober M, Paukovic M, Brunsting S, Daamen D (2011) Awareness, knowledge, beliefs, and opinions regarding CCS of the Dutch general public before and after information. Energy Procedia 4:6292-629

De Bruin WB, Wong-Parodi G (2014) The role of initial affective impressions in responses to educational communications: the case of carbon capture and sequestration (CCS). J Exp Psychol: Appl 20(2):126-135

Demski C, Butler C, Parkhill KA, Spence A, Pidgeon NF (2015) Public values for energy system change. Glob Environ Change 34:59-69

Demski C, Spence A, Pidgeon NF (2013) Summary findings of a survey conducted in August 2012-transforming the UK energy system: public values, attitudes and acceptability. UKERC, London

Devine-Wright P (2009) Rethinking NIMBYism: The role of place attachment and place identity in explaining place-protective action. J Community Appl Social Psychol 19(6):426-441

Devine-Wright P (ed) (2011) Renewable energy and the public: from NIMBY to participation. Earthscan, London

Eiser JR, van der Pligt J, Spears R (1995) Nuclear neighbourhoods: community responses to reactor siting. University of Exeter Press, Exeter

Eurobarometer (2011) Public Awareness and Acceptance of CO2 Capture and Storage. European Commission, Belgium

Fiorino D (1990) Citizen participation and environmental risk: a survey of institutional mechanisms. Sci, Technol Human Values 15(2):226-243

Global CCS Institute (2018) Large-scale CCS facilities. https://www. globalccsinstitutecom/projects/large-scale-ccs-projects. Accessed 10 Oct 2018

IEA (2013) Technology Roadmap Carbon Capture and Storage. http://www.ieaorg/ publications/freepublications/publication/CCSRoadmappdf. Accessed 10 Jan 2018

IPCC (2014) Climate Change 2014: Synthesis Report Contribution of Working Groups I, II and III to the Fifth Assessment Report of the Intergovernmental Panel on Climate Change. In: Pachauri RK, Meyer LA (eds) Core WritingTeam. IPCC, Geneva

Jones CR, Jones AR (2016) Two Blind Mice: It is Time for Greater Collaboration between Engineers and Social Scientists around the RDD\&D of Industrial Technologies. J Carbon Res C 2(2):16

Jones CR, Olfe-Kräutlein B, Kaklamanou D (2017a) Lay perceptions of Carbon Dioxide Utilisation technologies in the United Kingdom and Germany: An exploratory qualitative interview study. Energy Res Social Sci 34:283-293

Jones CR, Olfe-Kräutlein B, Naims H, Armstrong K (2017b) The social acceptance of carbon dioxide utilisation: a review and research agenda. Front Energy Res $5: 11$

Kahan DM, Jenkins-Smith H, Braman D (2011) Cultural cognition of scientific consensus. J Risk Res 14:147-174

Lenzi D, Lamb WF, Hilaire J, Kowarsch M, Minx JC (2018) Don't deploy negative emissions technologies without ethical analysis. Nature 561 (7723):303-305

L'Orange Seigo S, Arvai J, Dohle S, Siegrist M (2014) Predictors of risk and benefit perception of carbon capture and storage (CCS) in regions with different stages of deployment. Int J Greenh Gas Control 25:23-32

Lovan W, Murray M, Shaffer R (eds) (2004) Participatory governance. Routledge, London

Nisbet MC (2009) Communicating climate change: Why frames matter for public engagement. Environ: Sci Policy Sustain Dev 51(2):12-23

Petty RE, Cacioppo JT (1986) The elaboration likelihood model of persuasion. Academic Press, New York

Poumadère M, Bertoldo R, Samadi J (2011) Public perceptions and governance of controversial technologies to tackle climate change: nuclear power, carbon capture and storage, wind, and geoengineering. Wires: Clim Change 2 (5):712-727

Praetorius B, Schumacher K (2009) Greenhouse gas mitigation in a carbon constrained world: the role of carbon capture and storage. Energy Policy 37 (12):5081-5093
RCUK (2010) Progressing UK Energy Research for a Coherent Structure with Impact Report of the International Panel for the RCUK Review of Energy 2010. http://www.rcukacuk/documents/reviews/reviewpanelreport-pdf/. Accessed 15 Aug 2017

Reiner D, Riesch H, Kong Chyong C, Brunsting S, de Best-Waldhober M, Duetschke E, Oltra C, Lis A, Desbarats J, Pol M, Breukers S, Upham P, Mander S (2011) Opinion shaping factors towards CCS and local CCS projects: Public and stakeholder survey and focus groups. http://www. communicationnearco2eu/fileadmin/communicationnearco2/user/docs/ WP21_Report_Finalpdf. Accessed 15 Oct 2018

Upham P, Roberts T (2011) Public perceptions of CCS in context: Results of NearCO ${ }_{2}$ focus groups in the UK, Belgium, the Netherlands, Germany, Spain and Poland. Energy Procedia 4:6338-6344

Upham P, Oltra C, Boso À (2015) Towards a cross-paradigmatic framework of the social acceptance of energy systems. Energy Res Social Sci 8:100-112

van Egmond S, Hekkert MP (2012) Argument map for carbon capture and storage. Int J Greenh Gas Control 11:S148-S159

van Knippenberg D, Daamen DDL (1996) Providing information in public opinion surveys: motivation and ability effects in theinformation-and-choice questionnaire. Int J Public Opin Res 8:70-82

Wallquist L, Seigo SL, Visschers VHM, Siegrist M (2012) Public acceptance of CCS system elements: A conjoint measurement. Int J Greenh Gas Control 6:77-83

Wallquist L, Visschers VHM, Dohle S, Siegrist M (2011) Adapting communication to the public's intuitive understanding of CCS. Greenh Gases 1(1):83-91

Warren CR, Lumsden C, O’Dowd S, Birnie RV (2005) 'Green On Green': public perceptions of wind power in Scotland and Ireland. J Environ Plan Manag 48 (6):853-875

Wennersten R, Sun Q, Li H (2015) The future potential for Carbon Capture and Storage in climate change mitigation - an overview from perspectives of technology, economy and risk. J Clean Prod 103:724-736

Whitmarsh L, Corner A (2017) Tools for a new climate conversation: a mixedmethods study of language for public engagement across the political spectrum. Glob Environ Change 42:122-135

Whitmarsh L, Nash N, Upham P, Lloyd A, Verdon J, Kendall M (2015) UK public perceptions of shale gas hydraulic fracturing: The role of audience, message and contextual factors on risk perceptions and policy support. Appl Energy $15: 419-430$

Whitmarsh L, Swartling A, Jäger J (2009) Participation of experts and non-experts in a sustainability assessment of mobility. Environ Policy Gov 19:232-250

\section{Acknowledgements}

The research was undertaken as part of the EPSRC-funded CONTAIN project (GA/12F/ 101). We also gratefully acknowledge assistance with design and feedback on interpretation from Jon Harrington, Caroline Graham and Katherine Daniels from the British Geological Society

\section{Author contributions}

LW led the writing of the paper and analysis. DX led the data collection, with input from LW. LW, DX and CJ contributed to the study design and to writing and revising the paper.

\section{Additional information}

Competing interests: The authors declare no competing interests.

Reprints and permission information is available online at http://www.nature.com/ reprints

Publisher's note: Springer Nature remains neutral with regard to jurisdictional claims in published maps and institutional affiliations.

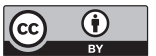

Open Access This article is licensed under a Creative Commons Attribution 4.0 International License, which permits use, sharing, adaptation, distribution and reproduction in any medium or format, as long as you give appropriate credit to the original author(s) and the source, provide a link to the Creative Commons license, and indicate if changes were made. The images or other third party material in this article are included in the article's Creative Commons license, unless indicated otherwise in a credit line to the material. If material is not included in the article's Creative Commons license and your intended use is not permitted by statutory regulation or exceeds the permitted use, you will need to obtain permission directly from the copyright holder. To view a copy of this license, visit http://creativecommons.org/ licenses/by/4.0/.

(C) The Author(s) 2019 